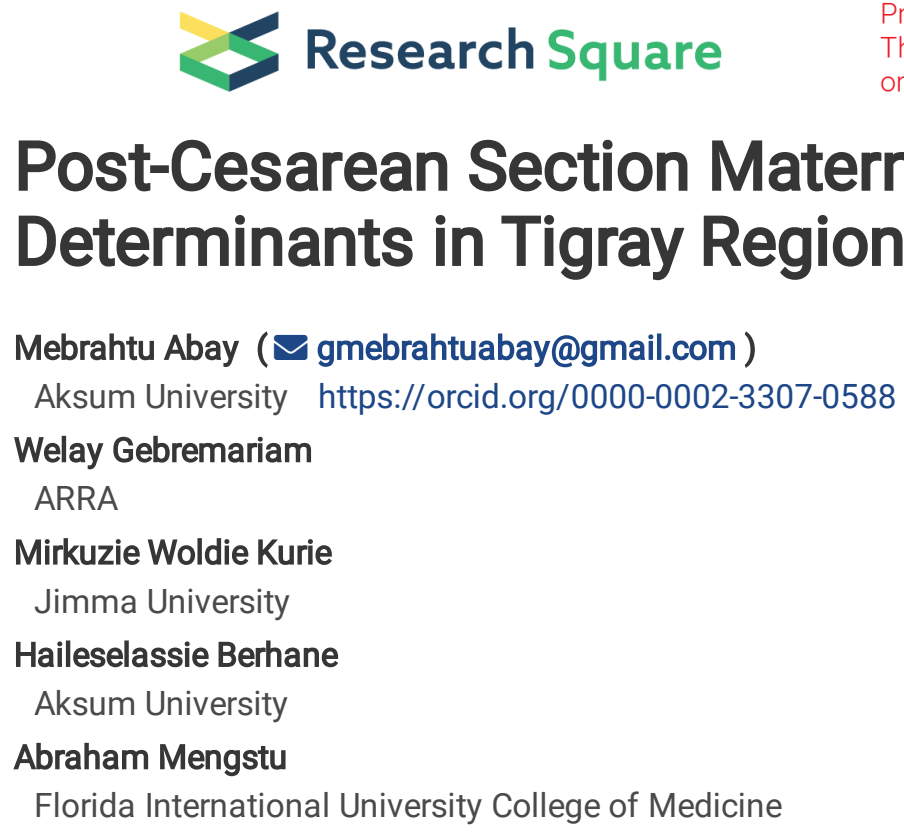

\title{
Post-Cesarean Section Maternal Health Outcome and its Determinants in Tigray Regional State, North Ethiopia.
}

Research article

Keywords: Cesarean Section, Maternal health outcome, Tigray, Ethiopia

Posted Date: October 29th, 2019

DOI: https://doi.org/10.21203/rs.2.16563/v1

License: (c) (i) This work is licensed under a Creative Commons Attribution 4.0 International License. Read Full License 


\section{Abstract}

Back ground Cesarean section rate is increasing worldwide. However, the World Health Organization has declared that there is insufficient information on maternal outcome following cesarean section for decision making.

Objective The aim of this study was to assess post cesarean section maternal outcome and its associated factors availing evidence for practice and policy.

Methods Institution based cross-sectional study was conducted among 357 mothers who underwent cesarean section in six selected public general hospitals of Tigray regional State, Ethiopia. Mothers were followed for the duration of post-operative period until they became safe for discharge. The maternal outcomes were categorized into either adverse or good outcomes depending on whether mothers develop any cesarean section related morbidity or not. Logistic regression model was constructed to determine the AOR and $95 \% \mathrm{Cl}$ of independent factors associated with maternal outcome following cesarean section.

Results The proportion of adverse maternal outcome was $19.3 \%$ with $95 \% \mathrm{Cl}$ of $(15.7 \%-23.8 \%)$. Route of anesthesia administration $(A O R=0.296,95 \% \mathrm{Cl}: 0.126-0.695)$ and referral status (AOR $=0.371,95 \% \mathrm{Cl}: 0.214-0.641)$ were statistically significant factors associated with maternal outcome following cesarean section.

Conclusion There was high proportion of adverse maternal outcome. General anesthesia and referral from lower health facilities were associated with higher risk of post-CS adverse maternal outcome. Equipping lower level health facilities with the human and material capacity for timely detection of CS indications and provision of cesarean section services could decrease the number of referrals and subsequent delays that lead to adverse maternal outcome.

\section{Background}

Cesarean section (CS) is a type of surgery performed when vaginal delivery would put the life of the mother or the baby at risk. Sometimes, it is also performed upon pregnant mother's request without any medical indication.

According to the 2010 WHO report, approximately 18.5 million cesarean sections are performed annually worldwide [1]. Nowadays, CS rate is increasing across the world [3]. According to the 2012 national vital statistics report the rate of cesarean section was 32.8\% in the United States of America[4]. Similar surveys conducted in 2007 and 2008 among leading Asian countries found out that the CS rates were $46 \%$ (China), 36\% (Vietnam) and 34\% (Thailand). Similarly, a study conducted in a private clinic in South Africa showed a cesarean section rate of $60.4 \%[5]$ while the rate in Nigeria was found to be $11.3 \%[6]$.

Likewise in the rest of the world, cesarean section rate is increasing in Ethiopia. Some studies addressing the rates of cesarean sections were conducted in Gurage zone (27.6\%), Bahir-Dar (25.4\%) and Mizan Aman general hospital (21.2\%) [7-9].

Indications and reasons for cesarean section are widely different across countries and institutions [10]. However, most commonly noted risk factors and indications are increased maternal age, increased parity, preterm labor, extremes of neonatal birth weight, previous cesarean section, being educated, using private clinic, attending antenatal care (ANC) with the same physician and getting richer economically [11-14].

The rate of cesarean section and its outcome are under an ongoing argument. In medium and high income countries, association was not found between cesarean section rates and maternal outcomes[15]. On the other hand, cesarean section rates of up to $15 \%$ showed good maternal health outcome [16] although cesarean section rate of more than $10 \%$ was not associated with decreasing maternal mortality [17].

The outcome of multiple cesarean sections is also unclear. A woman having multiple cesarean sections is highly exposed to uterine rupture, hysterectomy and bleeding [18]. However, a study conducted in Thailand showed that one previous cesarean section and two or more previous cesarean sections had no difference on maternal complications [19].

In general, the rate of cesarean section is increasing worldwide. However, according to the $2015 \mathrm{WHO}$ statement, the effects of cesarean section rates on maternal morbidity, psychological or social wellbeing remained unclear [2]. In addition, the level of adverse maternal outcome following CS remains unclear [20-22]. Therefore, this study aimed at addressing the information gap on

Page $2 / 11$ 
maternal outcome following cesarean section in public hospitals of Tigray Regional State, North Ethiopia. Findings of the study will guide health care practice and policy making.

\section{Methods}

\section{Study setting and design}

A cross-sectional study was conducted in Tigray Regional State, North Ethiopia. The State has seven administrative Zones. There are fourteen public general hospitals, two specialized teaching and referral hospitals, twenty primary hospitals and two hundred and four health centers in the State.

The study was conducted on women who underwent cesarean section in the six randomly selected public general hospitals of Tigray Regional State from August, 10 to September, 202016.

\section{Sample size determination and sampling}

A single population proportion estimation formula was used to determine the sample size by assuming a previous adverse maternal outcome proportion of 33.3\% [23], $5 \%$ level of significance and $5 \%$ assumption of non-response rate yielding a total of 359 study participants. Sample size was allocated to six randomly selected public general hospitals proportional to their previous number of cesarean section reports. Finally, the study participants were selected consecutively until the require sample is reached. Data were collected from mothers who underwent cesarean section and fulfilled the inclusion criteria. All mothers who had given birth through cesarean section at a gestational age of 28 weeks or above were included in the study.

\section{Data collection tools and analysis}

Structured questionnaire was used to collect the data from the patients. A structured checklist was used to collect secondary data from medical records and patient registration books. First data addressing socio-demographic factors, and reproductive and obstetric history were collected from the mothers through face-to-face interview. Then data on maternal outcomes, indications for cesarean section, medications given, number of cesarean sections, route of anesthesia administered, professional level of the surgeon and other associated risk factors were collected from patient medical records. Midwives and nurses were selected and trained for two days on the objective of the research and data collection procedures. Data on post-CS maternal outcome were collected from the start of the surgery until the time of discharge from the respective hospitals.

Data were entered into computer using SPSS version 22.0 software. Bivariable and multivariable logistic regression analysis models were used. The maternal outcomes were classified as either adverse or good outcome. A woman was said to have adverse maternal outcome when serious complications including uterine rupture, intrapartum or post partum hemorrhage, endometritis, wound infection, maternal death or others were observed following cesarean section. On the other hand, women without any of the above complications until discharged from the hospital were classified as having a good maternal outcome.

AOR with $95 \%$ confidence interval $(\mathrm{Cl})$ and P-value of less than 0.05 were used to identify factors associated with maternal outcome. Goodness- of - fit of the model was measured using Hosmer and Lemeshow test ( $p$-value $=0.887$ ). Variables that had statistically significant association in the bi-variable logistic regression model were entered into multivariable logistic regression. A forward method was applied in the multivariable logistic regression model to identify the independent determinant factors of maternal outcome following CS. Multicolinearity among variables were also checked using Variance Inflation Factor (VIF), and found that there is no multicolinearity (the minimum VIF value was 12.46).

\section{Results}

A total of 357 mothers who underwent cesarean section were included in the study, with a $99.4 \%$ response rate.

\section{Socio-demographic characteristics of the mothers}

Page 3/11 
The mean age of the mothers was 21.5 years with a (SD) standard deviation of 3.9 years. About two-third (69.2\%) and (63.0\%) of the respondents were urban residents and married, respectively. Majority (92.2\%) of the mothers were Orthodox Christian followers. Less than half $(42.9 \%)$ of the total respondents were farmers by occupation. Only $78(21.8 \%)$ were unable to read or write. About $45 \%$ of the respondents had their own house while $43 \%$ of the respondents were living in rental houses. The mean family size of the household of the mothers was 3.9 family members SD of 1.9 family members (Table 1 ).

Table 1: Socio-demographic, obstetric characteristics of women who underwent CS, Tigray Regional State, Ethiopia, 2016.

\begin{tabular}{|c|c|c|c|}
\hline Variables & Categories & Number & Percent \\
\hline \multirow[t]{6}{*}{ Age (in years) } & $15-19$ & 21 & 5.9 \\
\hline & $20-24$ & 98 & 27.5 \\
\hline & $25-29$ & 118 & 33.1 \\
\hline & $30-34$ & 69 & 19.3 \\
\hline & $35-39$ & 34 & 9.5 \\
\hline & $40-44$ & 17 & 4.8 \\
\hline \multirow[t]{4}{*}{ Educational status } & No formal education & 78 & 21.8 \\
\hline & Primary school & 100 & 28.0 \\
\hline & Secondary school & 104 & 29.1 \\
\hline & Diploma and above & 75 & 21.0 \\
\hline \multirow[t]{2}{*}{ Residence } & Rural & 110 & 30.8 \\
\hline & Urban & 247 & 69.2 \\
\hline \multirow[t]{3}{*}{ Home ownership status } & Own & 162 & 45.4 \\
\hline & Rent & 153 & 42.9 \\
\hline & Family & 42 & 11.8 \\
\hline \multirow[t]{5}{*}{ Occupational status of the husband } & Farmer & 94 & 26.3 \\
\hline & Trader & 93 & 26.1 \\
\hline & Employed & 132 & 40.0 \\
\hline & Daily laborers & 14 & 3.9 \\
\hline & Has no work & 24 & 6.7 \\
\hline \multirow[t]{4}{*}{ Family size of the house hold } & $\leq 2$ family members & 78 & 21.9 \\
\hline & 3 family members & 116 & 32.5 \\
\hline & 4 family members & 64 & 17.9 \\
\hline & $\geq 5$ family members & 99 & 27.7 \\
\hline
\end{tabular}

\section{Past obstetric and reproductive characteristics of the mothers}

Analysis of past obstetric and reproductive history showed that two hundred thirty two (65\%) mothers were multiparous. Forty one $(11.5 \%)$ of the total respondents had history of at least one abortion and $9(2.5 \%)$ of them had history of at least one stillbirth. Majority (72\%) of the respondents used modern family planning methods to prevent unwanted pregnancy. Eighty nine $89(24.9 \%)$ mothers had at least one morbidity during pregnancy period. Elective cesarean section constituted $11.2 \%$ of the total CS deliveries. Majority $(331,92.7 \%)$ of the cesarean sections were done under spinal anesthesia. Prophylactic antibiotics were given to almost all (99.4\%) women who underwent cesarean section. (Table 2).

Table 2: Past obstetric and reproductive characteristics of women who underwent CS, Tigray Regional state, Ethiopia, 2016. 


\begin{tabular}{llll}
\hline Variables & Categories & Number & Percent \\
\hline Outcome of last pregnancy & No history of pregnancy & 127 & 35.6 \\
& Child alive & 170 & 47.6 \\
& Abortion & 41 & 11.5 \\
& Still birth & 9 & 2.5 \\
& Child died & 10 & 2.8 \\
\hline Referred from lower health facility & Yes & 156 & 43.7 \\
& No & 201 & 56.3 \\
\hline Gestational age in completed weeks & $28-36$ & 36 & 10.1 \\
& $37-39$ & 308 & 86.3 \\
& $\geq 40$ & 13 & 3.6 \\
\hline History of family planning use & Yes & 257 & 72.0 \\
History of ANC visit during last pregnancy & No & 100 & 28.0 \\
& Yes & 352 & 98.6 \\
& No & 5 & 1.4 \\
\hline Timing of C/S & First stage of labor & 280 & 78.4 \\
& $2^{\text {nd }}$ stage of labor & 37 & 10.4 \\
& Elective & 40 & 11.2 \\
\hline Type of anesthesia administered during C/S & General anesthesia & 26 & 7.3 \\
& Spinal anesthesia & 331 & 92.7 \\
\hline
\end{tabular}

\section{Post-CS Maternal outcome}

Among the women who underwent CS, $69((19.3 \%, 95 \% \mathrm{Cl}(15.7 \%-23.8 \%))$ had one or another form of adverse maternal outcome. The major short-term complications observed were wound infection $25(7.0 \%)$, endometritis $13(3.6 \%)$ and bleedings requiring blood transfusion $10(2.8 \%)$; whereas hysterectomy $6(1.7 \%)$, uterine rupture $2(0.6 \%)$ and maternal death $1(0.28 \%)$ were the major long term and serious maternal complications observed. Mothers stayed in hospitals for an average of $4.91 \pm 2.34$ days.

Determinants of post-CS Maternal outcome: Educational level of partners, outcome of last pregnancy, stage of labor while CS is performed, referral status and residence showed statistically significant association with the development of an adverse maternal outcome in a bi-variable logistic regression analysis. After multivariable binary logistic regression was applied, only two variables were significantly associated with adverse maternal outcome. Mothers who were referred from lower setup institutions were 2.71 times more likely to develop adverse maternal outcome than those who came to the general hospitals directly with AOR of $2.71(95 \% \mathrm{Cl}(1.34,5.47))$. The route of anesthesia administration was the second variable that significantly affected maternal health outcome. Mothers who received general anesthesia were 3.14 times more likely to develop any adverse maternal health outcome as compared to those who received spinal anesthesia with AOR of 3.14 (95\% Cl (1.24, 8.01)) (Table 3).

Table 3: Factors associated with maternal health outcomes following cesarean section in public general hospitals of Tigray Regional State, Ethiopia, 2016. 


\begin{tabular}{|c|c|c|c|c|c|}
\hline \multirow[t]{2}{*}{ Variables } & \multirow[t]{2}{*}{ Categories } & \multicolumn{2}{|c|}{ Maternal } & \multirow[t]{2}{*}{ COR (95\% CI) } & \multirow[t]{2}{*}{ AOR (95\% CI) } \\
\hline & & Good MHO & $\begin{array}{r}\text { Adverse } \\
\text { MHO }\end{array}$ & & \\
\hline \multirow[t]{2}{*}{ Referral status } & Not referred & $176(87.6 \%)$ & $25(12.4 \%)$ & 1 & 1 \\
\hline & Referred & $112(71.8 \%)$ & $44(28.2 \%)$ & $\begin{array}{r}2.77(1.60, \\
4.77)\end{array}$ & $\begin{array}{r}2.71(1.34 \\
5.47)^{*}\end{array}$ \\
\hline \multirow{4}{*}{$\begin{array}{r}\text { Maternal educational } \\
\text { status }\end{array}$} & No formal education & $59(75.6 \%)$ & $19(24.4 \%)$ & 1 & 1 \\
\hline & Primary school & $81(81.0 \%)$ & $19(19.0 \%)$ & $0.73(0.36,1.49)$ & $1.03(0.45,2.36)$ \\
\hline & Secondary school & $92(88.5 \%)$ & $12(11.5 \%)$ & $\begin{array}{r}0.40(0.18 \\
0.89)\end{array}$ & $0.95(0.35,2.57)$ \\
\hline & Diploma and above & $56(74.7 \%)$ & $19(25.3 \%)$ & $\begin{array}{r}1.05(0.51 \\
2.19)\end{array}$ & $\begin{array}{r}3.45(0.16 \\
10.39)\end{array}$ \\
\hline \multirow[t]{4}{*}{$\begin{array}{r}\text { Husband's educational } \\
\text { status }\end{array}$} & $\begin{array}{l}\text { No formal } \\
\text { education }\end{array}$ & $40(70.2 \%)$ & $17(29.8 \%)$ & 1 & 1 \\
\hline & Primary school & $78(78.0 \%)$ & $22(22.0 \%)$ & $0.66(0.17,1.38)$ & $0.80(0.34,1.87)$ \\
\hline & Secondary school & $65(83.3 \%)$ & $13(16.7 \%)$ & $\begin{array}{r}0.47(0.21 \\
1.07)\end{array}$ & $0.50(0.17,1.46)$ \\
\hline & Diploma and above & $105(86.1 \%)$ & $17(13.9 \%)$ & $\begin{array}{r}0.38(0.18 \\
0.81)\end{array}$ & $0.38(0.12,1.26)$ \\
\hline \multirow[t]{4}{*}{ Husband's occupation } & Farmer & $67(71.3 \%)$ & $27(28.7 \%)$ & 1 & 1 \\
\hline & Trader & $74(79.6 \%)$ & $19(20.4 \%)$ & $\begin{array}{r}0.64(0.33) \\
1.25)\end{array}$ & $1.45(0.57,3.69)$ \\
\hline & Employed & $112(84.8 \%)$ & $20(15.2 \%)$ & $\begin{array}{r}0.44(0.23 \\
0.85)\end{array}$ & $0.99(0.36,2.71)$ \\
\hline & Others & $35(92.1 \%)$ & $3(7.9 \%)$ & $\begin{array}{r}0.21(0.06 \\
0.75)\end{array}$ & $0.36(0.09,1.52)$ \\
\hline \multirow[t]{2}{*}{ Residence } & Rural & $78(70.9 \%)$ & $32(29.1 \%)$ & $\begin{array}{r}2.33(1.38, \\
3.99)\end{array}$ & $1.37(0.61,3.05)$ \\
\hline & Urban & $210(85.0 \%)$ & $37(15.0 \%)$ & 1 & 1 \\
\hline \multirow[t]{2}{*}{ Type of C/S } & Emergency C/S & $260(80.5 \%)$ & $63(19.5 \%)$ & $\begin{array}{r}1.13(0.45 \\
2.85)\end{array}$ & $1.48(0.54,4.04)$ \\
\hline & Elective & $28(82.4 \%)$ & $6(17.6 \%)$ & 1 & 1 \\
\hline \multirow[t]{2}{*}{ Type of Anesthesia } & General anesthesia & $15(57.7 \%)$ & $11(42.3 \%)$ & $\begin{array}{r}3.45(1.51 \\
7.90) \\
\end{array}$ & $\begin{array}{r}3.14(1.24 \\
8.01)^{*}\end{array}$ \\
\hline & Spinal anesthesia & $273(82.5 \%)$ & $58(17.5 \%)$ & 1 & 1 \\
\hline \multirow[t]{4}{*}{ Family size } & Family size $\leq 2$ & $58(74.4 \%)$ & $20(23.6 \%)$ & 1 & 1 \\
\hline & Family size 3 & $101(87.1 \%)$ & $15(12.9 \%)$ & $\begin{array}{r}0.43(0.21 \\
0.91) \\
\end{array}$ & $0.44(0.19,1.98)$ \\
\hline & Family size 4 & $52(81.3 \%)$ & $12(18.7 \%)$ & $0.67(0.30,1.50)$ & $0.70(0.29,1.70)$ \\
\hline & Family size $\geq 5$ & $77(77.8 \%)$ & $22(22.2 \%)$ & $0.83(0.41,1.66)$ & $0.59(0.25,1.37)$ \\
\hline
\end{tabular}

AOR: Adjusted Odds Ratio, COR: Crude Odds Ratio, CI: Confidence Interval, C/S: Cesarean Section, MHO: Maternal Health Outcome, *Significant at p-value $<0.05$.

\section{Discussion}

This study assessed maternal health outcomes following cesarean section among mothers who gave birth at public general hospitals of Tigray regional State, Ethiopia. Cephalo-pelvic disproportion/CPD (18.5\%, $95 \% \mathrm{Cl}(14.71 \%, 22.77 \%))$, non-reassuring fetal distress (18.2\%), 95\% Cl (14.46\%, 22.47\%)) and malpresentation and malposition $(15.4 \%, 95 \% \mathrm{Cl}(11.94 \%, 19.43 \%))$ were the most common indications for cesarean section. This result was consistent with studies conducted in other parts of Ethiopia [8] and Nigeria [24]. 
About $19.32 \%$ [95\% Cl $(15.48 \%, 23.67 \%)]$ of the mothers who underwent CS developed one or another form of adverse maternal health outcome. A study conducted in Jimma also reported a $20 \%$ adverse maternal health outcome in mothers who underwent cesarean section [23]. However, the rate is much lower than the findings in Karachi, Pakistan (36.7\%) [25] or Finland (27\%) [26]. These differences could be attributed to nursing care differences.

Wound infection was the commonest short term maternal adverse outcome diagnosed in this study (7.0\%) $(95 \% \mathrm{Cl}(4.69 \%$, $10.02 \%)$ ) similar to the findings from a study in Nigeria [27] but less than all institution based findings in Ethiopia [25, 28]. This difference could be due to the different types of facilities in the different studies. The rate of post-partum hemorrhage in this study was $1.68 \%(95 \% \mathrm{Cl}(0.684 \%, 3.46 \%))$ which was similar to what was found in Australia and central Saudi Arabia [29, 30] but much lower than the finding from Pakistan (22\%) [25]. Endometritis, uterine rupture, hysterectomy and transfusion requiring bleedings occurred in $3.36 \%, 0.6 \%, 1.7 \%$ and $2.8 \%$ of the women respectively comparable with complication rates among mothers with prior CS scar [18]. There was one $(0.28 \%(95 \% \mathrm{Cl} 0.27-0.87))$ maternal death similar to findings in Sub Saharan Africa and other parts of Ethiopia $[7,9,31]$ but less than the findings from Nigeria or India [32, 33]. This variations might be due to differences in sample size.

Mothers who were referred from lower health care institutions were more likely to develop adverse maternal health outcome than those who had un-referred access to the general hospitals. This result was consistent with studies done in Ethiopia [34] and Nigeria [35]. This could partly be because more sever obstetric complications are more likely to be referred from lower healthcare facilities. Any delay model could also be responsible for the relatively higher risk of adverse maternal outcome observed among mothers who were referred to the general hospitals.

Mothers who underwent cesarean section under general anesthesia were more likely to develop adverse maternal health outcome compared to those who had cesarean section under spinal anesthesia. Conversely, mothers who underwent CS under spinal anesthesia had fewer less risk of adverse maternal outcome. This was similar to findings from Turkey [36], southern [37] and central [35] parts of Ethiopia. The reasons could be the increased risk of uterine atony leading to bleeding and incidental organ injuries that were higher in mothers who underwent CS under general anesthesia $[39,40]$.

Adverse maternal outcome rates were different among hospitals possibly because of differences in post-operative care of the hospitals or differences in the number of late stage referrals to better serving hospitals.

\section{Conclusion}

The rate of adverse maternal outcome following cesarean sections was high. Mothers' referred from lower setup institutions and administration of general anesthesia during $\mathrm{C} / \mathrm{S}$ was factors significantly associated with adverse maternal health outcomes following cesarean sections. Lower health facilities setup should better be equipped with essential equipment, materials and human resources to perform cesarean sections and hence decrease maternal referrals.

\section{Declarations}

\section{Ethical approval and consent to participate}

Ethical clearance was obtained from the Institutional Review Board of Aksum University, Ethiopia. Letter of support was obtained from the regional health bureau to respective health facilities. Further, all study participants were informed about the purpose of the study and written or verbal consent was obtained, as appropriate, from each study participants before data collection. Confidentiality was ensured by avoiding any identifiers of the study participants.

\section{Consent to publish}

Not applicable.

\section{Availability of data and materials}

All the data supporting the findings is contained within the manuscript, no additional data is needed.

\section{Competing interests}

Page $7 / 11$ 
The authors declare that they have no competing interests.

\section{Funding}

Financial cost of the research was covered by the principal investigator.

\section{Authors' contributions}

WG conceived and designed the study. WG, HB, AM and MA analyzed the data. HB, WG, MA, MT and AM wrote the paper and drafted the first version of the manuscript. HB, WG, MA, MT and AM: reviewed and approved the final version of the manuscript.

\section{Acknowledgements}

Our gratitude goes to supervisors, data collectors, respondents, administrative bodies of the respective health institutions and the regional health bureau for their involvements in this study.

\section{Authors' information}

WG has masters of degree in public health and currently working in Administration for Refugees and Returnee Affairs (ARRA), Ethiopia. HB has master of public health and currently working as a Lecturer in College of Health Sciences, Aksum University. MT is a professor of health service and health policy in the department of health service management and hospital administration, college of public health and medical sciences, Jimma University, Ethiopia. He is also vice president of institute of health in Jimma University, Ethiopia. MA is an assistant professor of epidemiology and is currently working in Department of public health, College of Health sciences, Aksum University. AM is a medical doctor and health policy analyst currently studying at the Department of Public Health Policy and Management, College of Public Health and Social Works, Florida International University.

\section{References}

1. Gibbons L, Jose M., Belizan, Jeremy A Lauer, Ana P Betrán, Merialdi M and Althabe F. The Global Numbers and Costs of Additionally Needed and Unnecessary Caesarean Sections Performed per Year: Overuse as a Barrier to Universal Coverage. World Health organization Report, 2010: p. 1-10.

2. WHO statement on Cesarean Section Rates,2015.

3. Mukherjee SN. Rising Cesarean Section Rate. The Journal of Obstetic and Gynecology of India, 2006. 56: p. 3.

4. Michelle J.K., Osterman, M.H.S., and Joyce A. Martin, M.P.H. Primary Cesarean Delivery Rates, by State: Results From the Revised Birth Certificate, 2006-2012. National Vital Statistics Reports, January 23,2014. Volume 63, Number 1: p. 11.

5. Ndadoo $\mathrm{N}$ et al. Rising rates of Caesarean sections: an audit of Caesarean sections in a specialist private practice. South African Family Practice:Published by Medpharm., Aug 15, 2014. 51(3): p. 6.

6. Daniel CN, Singh S. Caesarean delivery: An experience from a tertiary institution in north western Nigeria. Nigerian Journal of Clinical Practice, Jan-Feb 2016. 19(1): p. 7.

7.Moges A, Ademe BW., Akessa GM.Prevalence and Outcome of Caesarean Section in Attat Hospital, Gurage Zone, SNNPR, Ethiopia. iMedPub Journals, 2015. Vol.7 No 4:8: p. 1-6. 
8.Abebe FE , Gebeyehu AW., Kidane AN and Eyassu AG. Factors leading to cesarean section delivery at Felegehiwot referral hospital, Northwest Ethiopia: a retrospective record review. BioMedical Central 2016: p. 1-7.

9.Gutema H, Shimuye AS. Caesarean section and associated factors at Mizan Aman General Hospital Southwest Ethiopia. Journal of Gynecology and Obstetrics, 2014. Vol.2 No.3,: p. 37-41.

10.Festin, MR et al. Caesarean section in four South East Asian countries: reasons for, rates, associated care practices and health outcomes. BMC Pregnancy Childbirth, 2009. 9: p. 17.

11.Roshni R Patel, Tim J Peters. Deirdre J Murphy and the ALSPAC Study Team. Prenatal risk factors for Caesarean section. Analyses of the ALSPAC cohort of 12944 women in England. International Journal of Epidemiology, 2005. 34: p. 15.

12.P.M. Tebeu, E.Mboudou, G.Halle, E.Kongnyuy, E. Nkwabong and J.N.Fomulu. Risk Factors of Deliveryby Caesarean SectioninCameroon (2003-2004): A Regional Hospital Report. International Scholarly Research Network, 2011. 2011: p. 5.

13.Mendoza-Sassi RA, Almeida JC, Rodrigues da Silva P, Denardin G, Rodrigues MM. Risk factors for cesarean section by category of health service. Faculdade de Medicina, 2010. 44(1): p. 10.

14.Uilho A Gomes, A.ntonio AM Silva, Bettiol H, Marco A Barbieric. Risk factors for the increasing caesarean section rate in Southeast Brazil: a comparison of two birth cohorts, 1978-1979 and 1994. International Journal of Epidemiology 1998. 28: p. 8.

15.Althabe,F., Sosa C., Belizan, J.M., Gibbons,L., Jacquerioz, F. Bergel,E. Cesarean section rates and maternal and neonatal mortality in low-, medium-, and high-income countries: an ecological study. Birth, 2006. 33(4): p. 270-7.

16.Volpe, F.M. Correlation of Cesarean rates to maternal and infant mortality rates: an ecologic study of official international data. Rev Panam Salud Publica, 2011. 29(5): p. 303-8.

17.Ye, J., et al. Association between rates of caesarean section and maternal and neonatal mortality in the 21 st century: a worldwide population-based ecological study with longitudinal data. BJOG, 2016. 123(5): p. 745-53.

18.Mark B., et al Risk of Uterine Rupture With a Trial of Labor in Women With Multiple and Single Prior Cesarean Delivery. American college of Obstetricians and Gynecologists, 2006. Vol.108, No 1, July 2006: p. 12. 
19. Wuttikonsammakit P, Sukharoen N. Pregnancy outcomes of multiple repeated cesarean sections in King Chulalongkorn Memorial Hospital. J Med Assoc Thai, 2006. 89 Suppl 4: p. S81-6.

20.lyoke C.A.,et al. Risks associated with subsequent pregnancy after one caesarean section: A prospective cohort study in a Nigerian obstetric population. Niger J Clin Pract, 2014. 17(4): p. 442-8

21.Briand, V., et al. Maternal and perinatal outcomes by mode of delivery in senegal and mali: a cross-sectional epidemiological survey. PLoS One, 2012. 7(10): p. e47352.

22.Gebhardt G.S., et al., Maternal death and caesarean section in South Africa: Results from the 2011-2013 Saving Mothers Report of the National Committee for Confidential Enquiries into Maternal Deaths. S Afr Med J, 2015. 105(4): p. 287-91.

23.Ali Y. Analysis of caesarean delivery in Jimma Hospital, south-western Ethiopia. East Afr Med J, 1995. 72(1): p. 60-3.

24.Geidam, AD, Audu BM, Kawuwa BM and Obed JY. Rising trend and indications of caesarean section at the university of Maiduguri teaching hospital, Nigeria. Ann Afr Med, 2009. 8(2): p. 127-32.

25.Ghazi A, Karim F, Muhammad AH,Ali T, Jabbar S, maternal morbidity in emergency versus elective cesarean section at teritiary care hospital. J Ayub Med Coll Abbottabad, 2012. 24(1).

26.Pallasmaa, N. Cesarean section - Short term.Maternal Complications Related to the model of delivery , P. Professor Seppo Heinonen; MD, Editor. 2014: Finland. p. 86.

27.Fasubaa OB., et al. Uncomplicated Caesarean section: is prolonged hospital stay necessary? East Afr Med J, 2000. 77(8): p. 44851.

28.Fsseha N, Getachew A, Hiluf M, Gebrehiwot Y and Bailey P. A national review of cesarean delivery in Ethiopia. Int J Gynaecol Obstet, 2011. 115(1): p. 106-11.

29.Grace L., et al. Perinatal consequences of a category 1 caesarean section at term. BMJ Open, 2015. 5(e007248): p. 7.

30.Al-Kadrei et al. Increased cesarean section rate in Central Saudi Arabia: a change in practice or different maternal characteristics. International Journal of Women's Health 10 July 2015. 7: p. 8. 
31. Chu K, Cortier H, Maldonado F, Mashant T, Ford F, Trelles M. Cesarean Section Rates and Indications in Sub-Saharan Africa: A Multi-Country Study from Medecins sans Frontieres. Sept 2012. 7(9).

32.0jo VA, Adetoro 00, Okwerekwu FE. Characteristics of maternal deaths following cesarean section in a developing country. Int $\mathrm{J}$ Gynaecol Obstet, 1988. 27(2): p. 171-6.

33. Harde M., et al. Prospective evaluation of maternal morbidity and mortality in post-cesarean section patients admitted to postanesthesia intensive care unit. Journal of Anaesthesiology Clinical Pharmacology, October-December 2014. 30(4): p. 6.

34. https://link.springer.com/article/10.1186/s12884-018-1903-1

35. https://www.tandfonline.com/doi/full/10.1080/07399332.2014.943839

36. Saygıl Al, Özdamar O and Gün I. Comparison of maternal and fetal outcomes among patients undergoing cesarean section under general and spinal anesthesia: a randomized clinical trial. 2015. 133(3): p. 8.

37. https://www.semanticscholar.org/paper/Magnitude-of-maternal-complications-and-associated-MelkamuBelayneh/f198eea5d2f7439de5f172b8a64e6b2508084b18

38. MokonenS, Eshete A, Desta K, Molla Y. Maternal and Neonatal outcomes in mothers who undergo caesarean under General and spinal Anesthesia in Gandhi Memorial Hospital ,Addis Ababa. OMICS Publisher Group, 2015. 3(1): p. 5.

39.https://www.intechopen.com/books/cesarean-delivery/determining-factors-of-cesarean-delivery-trends-in-developing-countrieslessons-from-point-g-nat

40.https://www.researchgate.net/publication/301277279_Outcome_of_Induction_and_Associated_Factors_among_Term_and_Posterm_Mothers_Managed_at_Jimma_University_Specialized_Hospital_A_Two_Years'_Retrospective_Analysis 